University of Wollongong

Research Online

Faculty of Engineering - Papers (Archive)

Faculty of Engineering and Information

Sciences

$1-1-2009$

\title{
Towards the position control of conducting polymer trilayer bending actuators with integrated feedback sensor
}

Stephen John

University of Wollongong, swj56@uow.edu.au

Gursel Alici

University of Wollongong, gursel@uow.edu.au

Christopher D. Cook

University of Wollongong, chris_cook@uow.edu.au

Follow this and additional works at: https://ro.uow.edu.au/engpapers

Part of the Engineering Commons

https://ro.uow.edu.au/engpapers/3256

\section{Recommended Citation}

John, Stephen; Alici, Gursel; and Cook, Christopher D.: Towards the position control of conducting polymer trilayer bending actuators with integrated feedback sensor 2009, 65-70.

https://ro.uow.edu.au/engpapers/3256

Research Online is the open access institutional repository for the University of Wollongong. For further information contact the UOW Library: research-pubs@uow.edu.au 


\title{
Towards the Position Control of Conducting Polymer Trilayer Bending Actuators with Integrated Feedback Sensor
}

\author{
Stephen W. John, Gursel Alici, Christopher D. Cook
}

\begin{abstract}
Conducting polymers have a wide range of reversibly controllable properties, leading to a number of potentially useful devices for robotic applications, including actuators, sensors and batteries. Conducting polymers have the advantages of low weight, low cost, flexibility, small activation potentials $(<2 \mathrm{~V})$, biocompatibility and the ability to be manufactured using relatively straightforward techniques. Trilayer bending actuators which utilise the controllable change in volume of conducting polymers are potentially useful devices, but their speed and positioning ability must be improved. Significant research effort has been directed towards improving conducting polymer actuator performance through its chemistry, but the use of compensating control systems has had relatively little focus. This paper experimentally investigates three potential control systems for a trilayer bending actuator - feedforward gain control, feedforward inversion-based control and inversionbased PI control. It was found that the inversion-based PI control system provided the best performance, but the implementation utilised a large laser displacement sensor. To limit the requirement for such a large feedback sensor, a trilayer bending actuator with an integrated displacement sensor is proposed, exploiting the additional sensing capability of conducting polymers.
\end{abstract}

\section{INTRODUCTION}

Conducting polymers (CPs) are attractive not only for their ability to transport charge, but also for the number of their properties which can be reversibly controlled, including colour, volume, conductivity and porosity. Functional devices can be created by controlling the charge contained by the polymer. The polymer is flexible, lightweight and biocompatible [1], can operate in air or liquid environments and the potentials required to drive these changes are small, less than $2 \mathrm{~V}$ [2].

The wide range of properties demonstrated by conducting polymers could lead to low cost, all-polymer robotic devices. An all-polymer robot could interact with its environment using

Stephen W. John was with the School of Mechanical, Materials and Mechatronic Engineering, University of Wollongong, NSW 2522, Australia. $\mathrm{He}$ is now with Panasonic, 3-4 Hikaridai, Seika-Cho, Soraku-gu, Kyoto, Japan, (e-mail: john.stephen@jp.panasonic.com).

Gursel Alici is with the School of Mechanical, Materials and Mechatronic Engineering and the ARC Center of Excellence on Electromaterials Science,

University of Wollongong, NSW 2522, Australia (e-mail: gursel@uow.edu.au).

Christopher D. Cook is with the Faculty of Engineering, University of Wollongong, NSW 2522, Australia (phone: +61-24221-3062; e-mail: ccook@uow.edu.au). conducting polymer sensors [3, 4] and actuators [1, 5]; it could process information through $\mathrm{CP}$ transistor based computers [6] and be powered by conducting polymer batteries and solar cells [7-9]. Relatively simple techniques, such as ink-jet printing [10], can be used to directly deposit the polymer, which may lead to the construction of low-cost robotic devices on demand. However, before the idea can be realised, the individual conducting polymer devices must be optimised and controlled. Our recent research work has focussed on characterising and improving conducting polymer actuators, otherwise known as 'artificial muscles' [11-14].

Unlike electrostatic based actuation devices which are dependent on electric field, conducting polymer actuators operate on changes in the charge stored by the polymer, facilitating small input voltages. As the amount of charge is changed, ions are transferred into, or out of, the polymer structure to maintain electroneutrality, leading to the use of the term 'artificial muscle' in analogy to the operation of real muscle. These actuators can generate strains up to $39 \%$ [15], stresses up to $49 \mathrm{MPa}$ [16], potential biocompatibility [1] and have ability to be manufactured on various scales and by various processes.

Trilayer benders are a laminated type of conducting polymer actuator structure, comprising of two conducting polymer layers separated by a gold-coated porous substrate (Figure 1). The two conducting polymer layers act as positive and negative electrodes, changing volume as an electrical potential is applied across them. The porous substrate serves to electrically insulate the conducting polymer layers and storing the electrolyte required for operation. The primary benefit of the trilayer bending actuators is they have self-contained operation in air, unlike other configurations (such as linear devices) which are often required to be submerged in electrolyte. Trilayer bending actuators have been the focus of a number of characterisation and modelling efforts, with a number of performance limitations identified, including slow response times [14] and longer term positional drift [11, 14]. Additionally, large input voltages can cause rapid degradation of the polymer structure if not correctly applied $[17,18]$.

Significant research effort has been directed towards improving the stress and strain generated by conducting polymer actuators by optimising synthesis conditions, electrolyte type and material properties. The use of control techniques can improve performance beyond that possible by chemistry alone, by compensating for the dynamics of the device; however, previous applications of control techniques 
to trilayer bender actuators has been limited. Yao et. al. [14] have previously applied PID control to a trilayer bender, while Fang et. al. [19] have used a reduced complexity physicsbased model as part of a robust adaptive control system. In both cases, laser displacement sensors have been used to provide displacement feedback which may not be practical for all situations, particularly low-cost applications. As such, alternative control strategies would be beneficial to further improve performance without excessively increasing system complexity.

This paper aims to improve the speed and positioning capability of conducting polymer actuators, specifically trilayer bending actuators, through the use of model based control systems. Two feedforward strategies are experimentally characterised and compared to a feedback approach. Finally, a feedback control system incorporating an integrated conducting polymer sensor is proposed.

The paper is organized as follows: the experimental setup is described in Section II. Section III presents the control strategies investigated in this work and their experimental characterisation. An actuator with an integrated feedback sensor for positional control, based on the sensing ability of the trilayer structure, is proposed in Section IV. Conclusions and future work are presented in the final section.

\section{EXPERIMENTAL SETUP}

\section{A. Trilayer bender manufacture}

Conducting polymer trilayer bending actuators were manufactured using a three step process. First, a $120 \mathrm{~mm}$ square section of the porous poly(vinylidene fluoride) (PVDF) substrate was cut from a bulk roll and a thin conductive gold coating applied using a sputter coater. The conducting polymer polypyrrole was then electrochemically deposited onto the gold layer, using a constant current for 12 hours, generating approximately $1.8 \mu \mathrm{m}$ of polymer per hour. After growth, actuators were cut from the bulk sheet as required using a sharp blade. Full details of the synthesis procedure are presented in $[13,20]$.

\section{B. Measurement Equipment}

A custom experimental setup has been utilised to implement and characterise the trilayer bender control system and assess the performance, as illustrated in Figure 2. A National Instruments NI-6229 DAQ was used to generate the dynamic input signals. A second computer, running a MATLAB Real Time operating system was used to implement the control systems, calculating the control signal at a rate of $4 \mathrm{kHz}$. An eDAQ potentiostat was used to amplify the control signal, applying it to the actuator using an electrode clamp. A laser displacement sensor (micro-epsilon, NDCT-1700-10) was used to measure the tip displacement of the trilayer bender

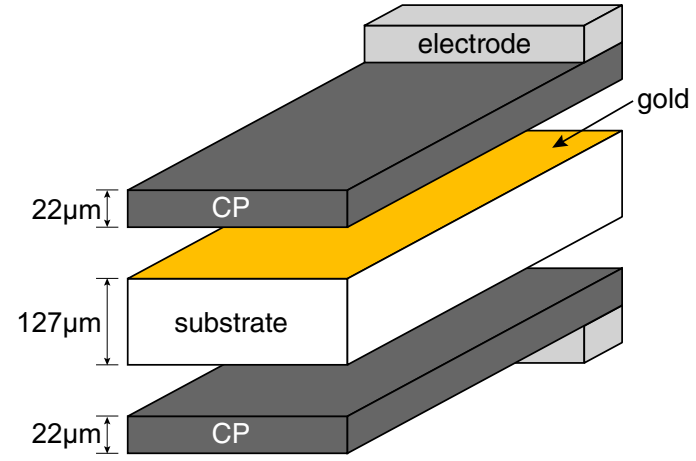

Figure 1: Exploded structure of the conducting polymer trilayer bender actuator, showing the two conducting polymer (CP) layers and the porous substrate.

actuator and provide feedback to the control system. An eDAQ datalogger was used to record the set point, applied voltage, current drawn and actuator displacement at $1 \mathrm{kHz}$.

\section{CONTROL Strategies}

Three potential trilayer bender actuator control systems are considered in this work. First a feedforward gain $(\mathrm{K})$ controller (Figure 3(a)) is used as a baseline upon which other control systems are compared. The actuator displacement is linear with input voltage $[20,21]$ and the reciprocal of this constant was used as the gain $\mathrm{K}$, here $0.12 \mathrm{~V} / \mathrm{mm}$. A transfer function model of the trilayer bending actuator displacement is used as the basis of two inversion-based control schemes - a feedforward (FF) inversion-based control system (Figure 3(b)) and a Proportional-Integral (PI) inversion-based control system (Figure 3(c)).

To implement the inversion-based control systems, a model of the actuator displacement is required. While models have been developed for the impedance of conducting polymer actuators [19,22], there are no physics-based models exist which can accurately represent the dynamic behaviour of a trilayer bender over a wide frequency range, due to the complex electrochemical behaviour of the system. As an alternative approach, we have identified empirical linear transfer model structures that can represent the frequency response of the trilayer bender actuator displacement as a function of input voltage [20,21], suitable for control system development. The model structure is of the form given in (1), and can suitably model the actuator displacement up to the resonant peak (Figure 4), while remaining valid for multiple actuator geometries [20].

Identification and modelling of the trilayer bender frequency response was performed prior to the experiment, while the calculation of the required control signal, $U_{c}(s)$, in response to a set-point, $Y_{d}(s)$, was performed in real-time using MATLAB. A low-pass filter, $H(s)$, has been used with the inverted transfer function model to make the system realisable. 


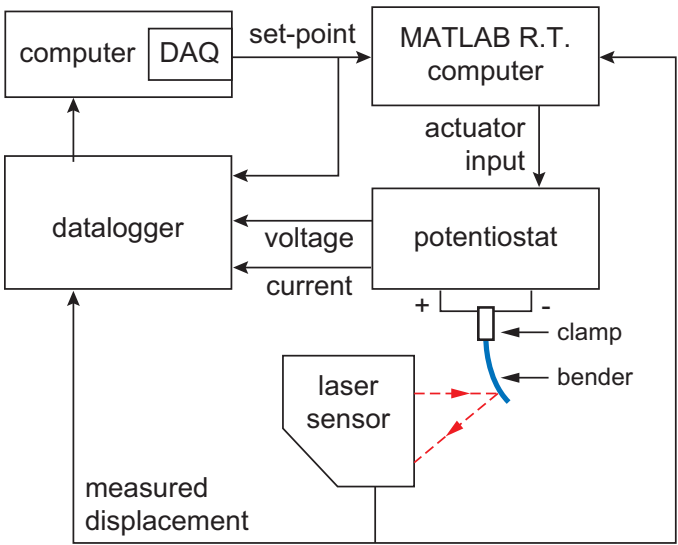

Figure 2: Schematic of the experimental setup.

(a)

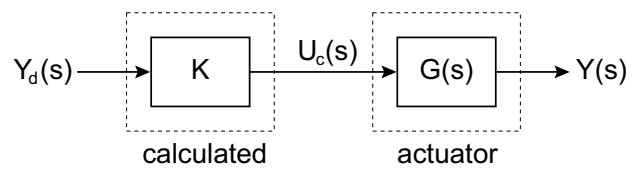

(b)

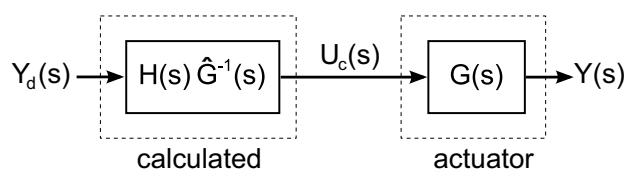

(c)

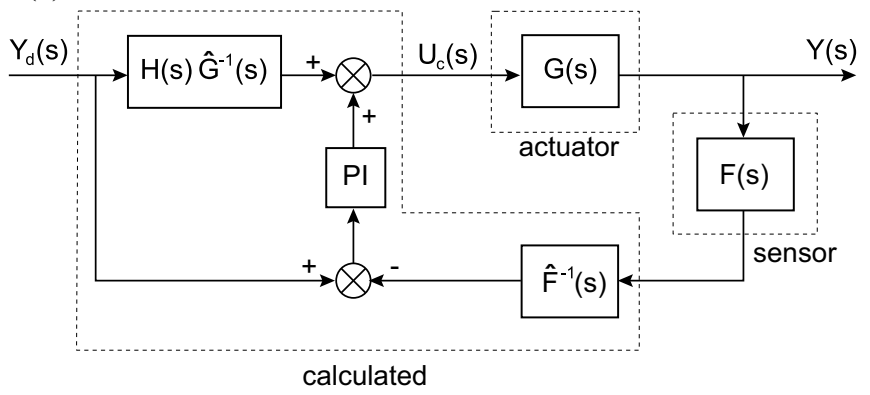

Figure 3: (a) Feedforward gain (K) control system, (b) Inversion-based feedforward (FF) control system, (c) Inversion-based Proportional-Integral (PI) control system.
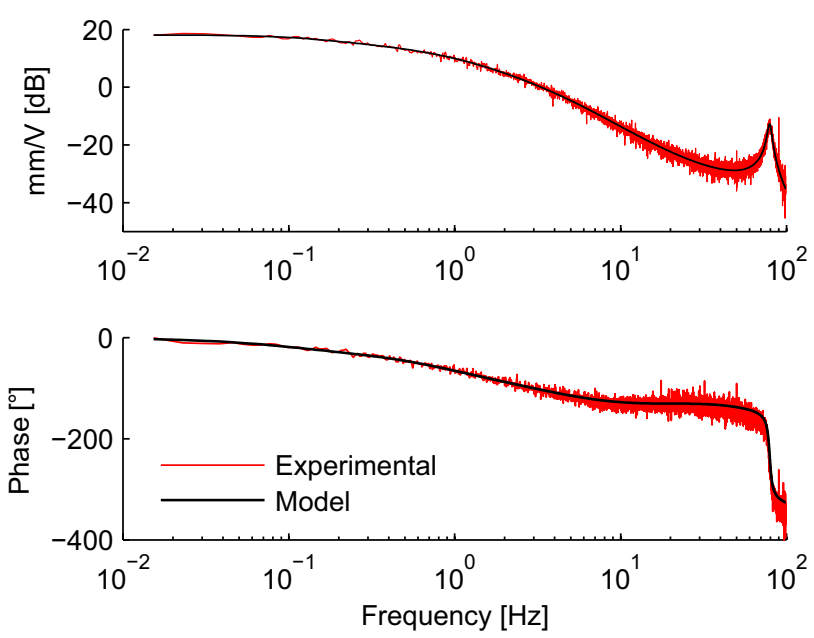

Figure 4: Frequency response of a conducting polymer trilayer bender actuator with a fitted transfer function model.

\section{A. Performance Characterisation}

The calculated control signals and resultant displacement of a $10 \mathrm{~mm}$ long, $2 \mathrm{~mm}$ wide trilayer bender actuator is shown in Figure 5 for the three control systems in response to a $0.4 \mathrm{~mm}$ step input. The calculated input voltages are less than $1 \mathrm{~V}$ in all cases, which does not damage the polymer. The $10 \%$ to $90 \%$ rise time of the PI controlled system is $45 \mathrm{~ms}$, compared to $51 \mathrm{~ms}$ for the inversion-based feedforward system and $6.8 \mathrm{~s}$ for the feedforward gain system used as a baseline. Both the inversion-based techniques improve the rise time of the actuator by over 130 times as compared to the feedforward gain control system. The steady state error at 2 seconds is minor for both the inversion-based controlled systems, while the feedforward gain controlled system does not reach the setpoint. The $5 \%$ settling time is reached in $100 \mathrm{~ms}$ for the inversion-based feedforward control system and $217 \mathrm{~ms}$ for the PI control system. The overshoot of the PI controlled system is also significant at $48 \%$, compared to $2 \%$ for the feedforward controlled system. Further tuning of the PI gains would reduce the magnitude of the overshoot, at the cost of an increased rise time. The performance of the inversion-based PI control systems can also be favorably compared to a previous PID control attempt reported in the literature, which showed a rise time of $132 \mathrm{~ms}$ (0 to $100 \%$ ) and a $5 \%$ settling time of approximately $1.4 \mathrm{~s}$ [14].

The calculated input voltage and resulting displacement of a $10 \mathrm{~mm}$ long, $2 \mathrm{~mm}$ wide trilayer bending actuator in response to a $0.4 \mathrm{~mm}$ step input is shown in Figure 6 for the three control systems tested over approximately 300 seconds. The two feedforward control systems show significant positional drift over the duration of the test, while the PI system shows zero steady state error due to the use of integral gain. This

$\hat{G}(s)=\frac{Y(s)}{U(s)}=k \frac{\prod_{m=1}^{5}\left(s-z_{m}\right)}{\prod_{n=1}^{6}\left(s-p_{n}\right)}$
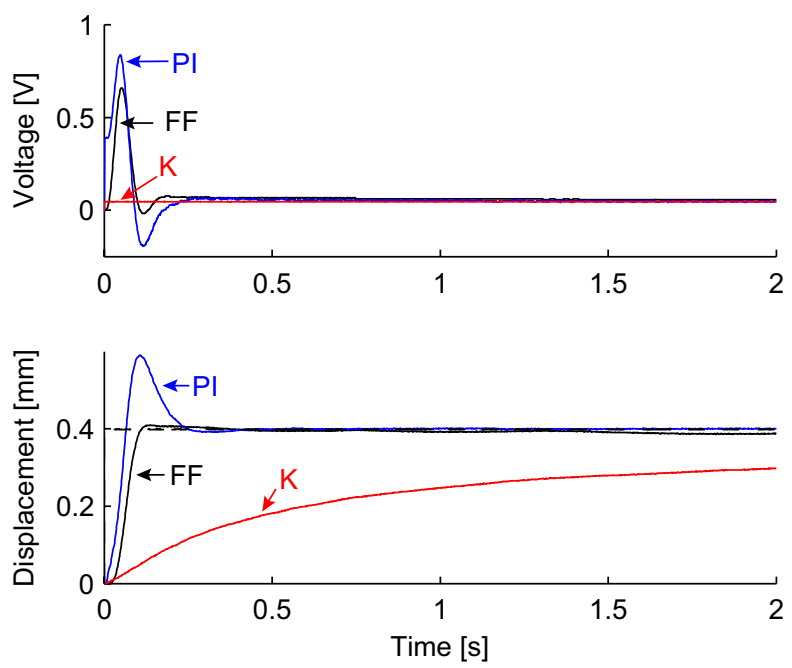

Figure 5: Input voltage and actuator displacement of a $10 \mathrm{~mm}$ long, $2 \mathrm{~mm}$ wide trilayer bender under feedforward gain, inversion-based feedforward and inversion-based PI control in response to a $0.4 \mathrm{~mm}$ step input. 
drift has been identified previously $[11,14]$ and is likely due to slow actuation processes, representing a significant source of positional error. The control voltages applied to the actuator after steady state has been reached (10 seconds) and at 297 seconds are shown in Table 1. In the absence of feedback, the two feedforward schemes cannot modify the voltage over this time period to compensate for the positional drift or forward relaxation of the actuator, while the PI based control system decreased the input by approximately $15 \%$.

The performance of a trilayer bender actuator in response to a $0.1 \mathrm{~Hz}$ sinusoidal input displacement is shown in Figure 7 under control of the two inversion-based systems. The PI based control system is better able follow the dynamic input signal, with an RMS error of $0.04 \mathrm{~mm}$, compared to the RMS error of $0.11 \mathrm{~mm}$ for the feedforward controlled system .

Of the three control systems identified here, the inversionbased PI approach provided the fastest rise times combined with minimal steady state error and better dynamic performance; however, this came at the cost of increased control system complexity, requiring a laser displacement sensor to provide position feedback. Both feedforward control approaches required less external hardware for
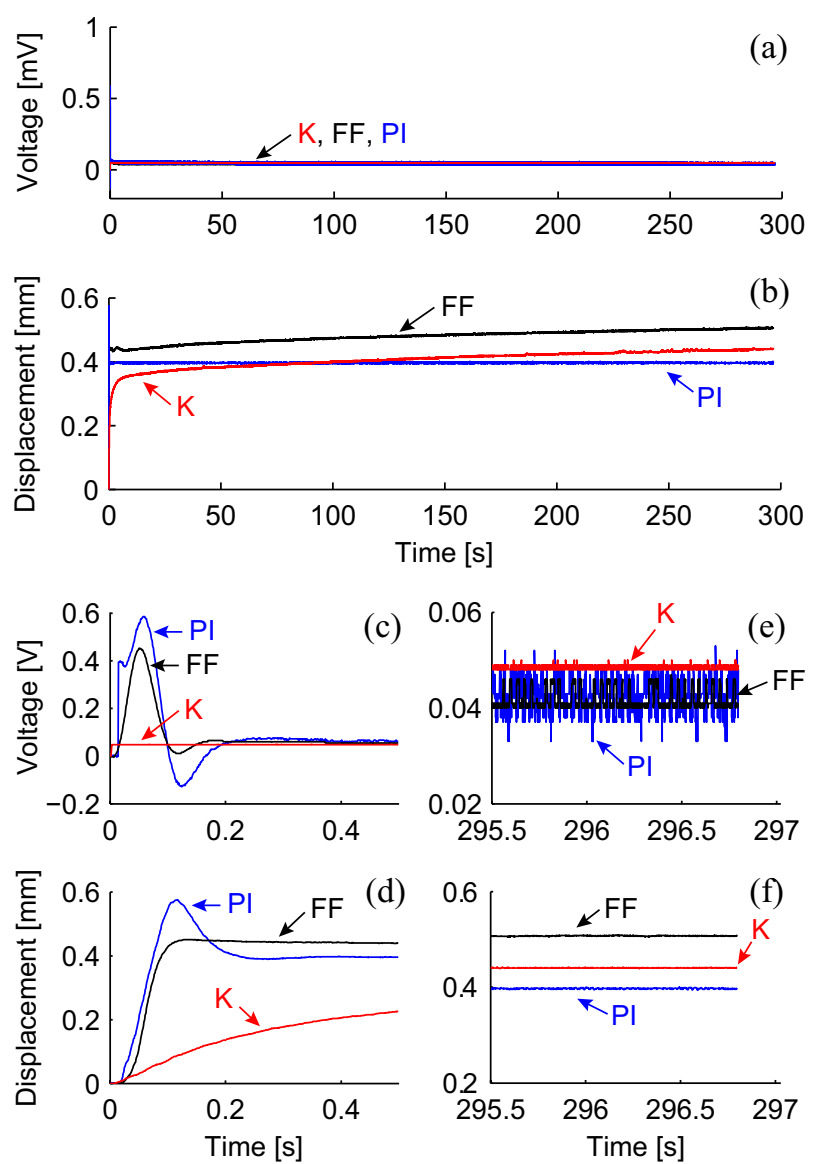

Figure 6: (a) Control signal voltage and (b) displacement response of a $10 \mathrm{~mm}$ long, $2 \mathrm{~mm}$ wide trilayer bender actuator to a $0.4 \mathrm{~mm}$ step input displacement under the control of the proportional gain $(\mathrm{K})$, inversion-based feedforward (FF) and inversion-based proportional-integral control (PI). The (c) voltage and (d) displacement of the first 0.5 seconds are shown, along 1 second of (e) voltage and (f) displacement from the end of the test. implementation and may be suitable for applications where feedback is difficult to implement, but they cannot deal with external disturbances or longer term positional drift. Additionally, the feedforward gain controller did not compensate for actuator dynamics, resulting in slow rise times in addition to the positional drift.

\section{Proposed Integrated FeEdBACK SENSOR}

Of the control systems tested in Section III, the PI inversionbased control system provided fast rise times and zero steady state error over long time periods; however, the implementation required the use of a laser displacement sensor to provide position feedback, which may not be practical for all applications. Conducting polymers can operate as mechanical sensors, generating a voltage or current in response to an external force or displacement $[4,12,23,24,25]$. It has been shown that the conducting polymer trilayer bending structure can also be used as a bending sensor without modification $[4,11]$. It is proposed that the trilayer bending sensor can be used in conjunction with a bending actuator to produce a lightweight and integrated sensor for feedback control.

The proposed integrated system containing a conducting polymer actuator and displacement feedback sensor is shown in Figure 8, comprising of the laminated trilayer bending actuator structure with a thin groove etched or cut to remove a thin section of conducting polymer and gold. This approach

TABLE 1

CONTROL INPUT VOLTAGES AT 10 SECONDS AND 297 SECONDS FOR THE THREE CONTROL SYSTEMS TESTED.

\begin{tabular}{cccc}
\hline \hline $\begin{array}{c}\text { Control } \\
\text { System }\end{array}$ & \multicolumn{2}{c}{ Voltage [V] } & Difference \\
[V] & $297 \mathrm{~s}$ & 0 \\
\hline $\mathrm{K}$ & 0.042 & 0.042 & 0 \\
$\mathrm{FF}$ & 0.048 & 0.048 & 0.008 \\
$\mathrm{PI}$ & 0.050 & 0.042 & \\
\hline \hline
\end{tabular}
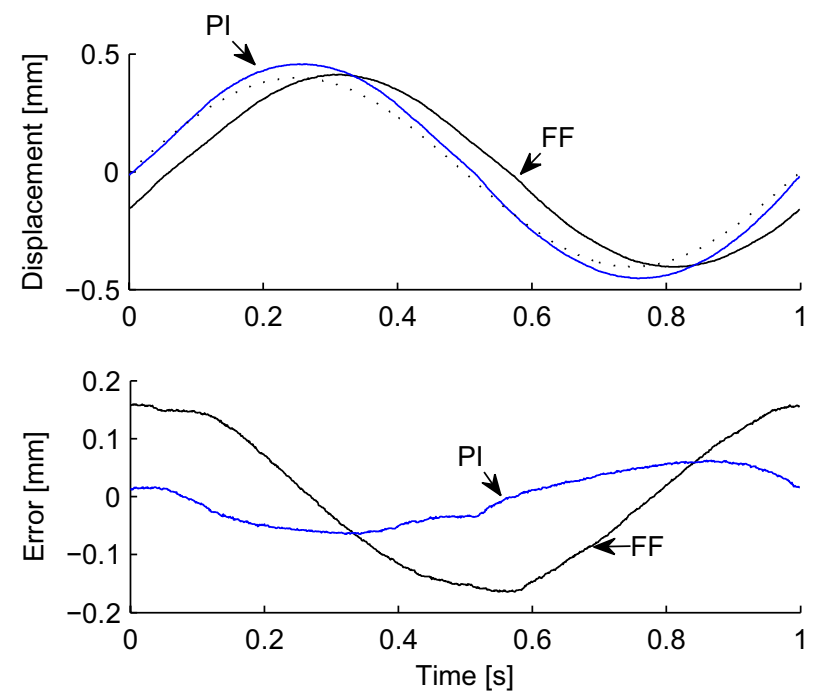

Figure 7: Response of a $10 \mathrm{~mm}$ long, $2 \mathrm{~mm}$ wide trilayer bender actuator to a $0.1 \mathrm{~Hz}$ input displacement, under PI and FF inversion-based control. The input signal is also shown (dotted). 
creates two electrically insulated trilayer structures, mechanically linked by the substrate, one forming the actuator and the other the feedback sensor.

An example of the frequency response of the trilayer bending sensor output is shown in Figure 9, demonstrating three characteristic traits: (a) a low-pass filter behaviour, (b) a distinctive peak at approximately $3 \mathrm{~Hz}$ and (c) a relatively constant output above $10 \mathrm{~Hz}$. This frequency response behaviour is consistent for both the voltage and current output of the device and can be modelled using a transfer-function of the form given in (2) [12]. As the sensor output varies with input frequency, any practical use of the device will require some computational analysis to identify the true dynamic displacement input from the measured current or voltage.

A schematic of the proposed system is presented in Figure 10, showing the integrated sensor and actuator device and a potential PI inversion-based controller. The model of the sensor output can be directly inverted without modification to obtain $\hat{F}^{-1}(s)$, given $m=n$, and is used to determine the actuator displacement from the sensor output.

$$
\hat{F}(s)=\frac{D(s)}{Y(s)}=k \frac{\prod_{m=1}^{4}\left(s-z_{m}\right)}{\prod_{n=1}^{4}\left(s-p_{n}\right)}
$$

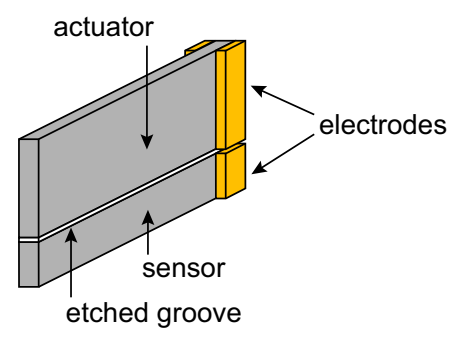

Figure 8: Schematic of the proposed conducting polymer actuator with integrated feedback sensor.
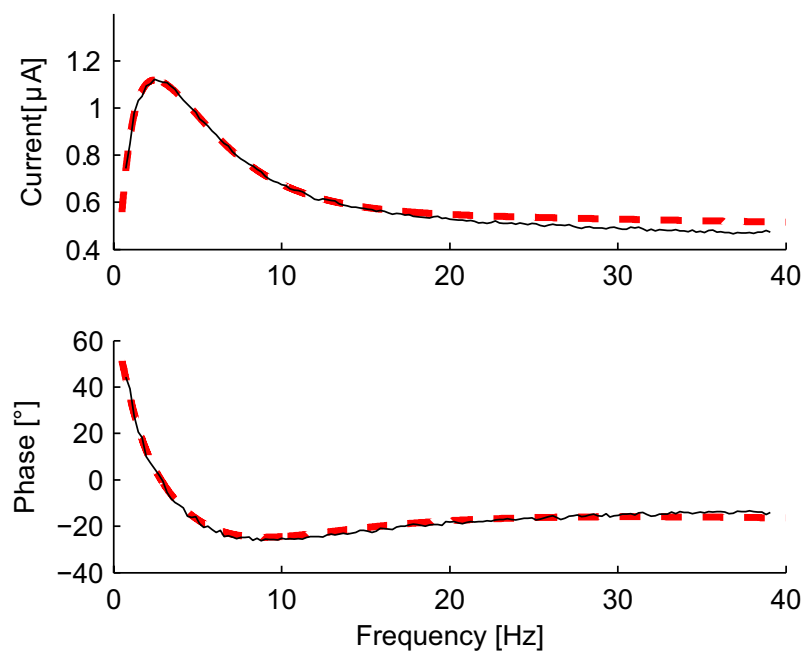

Figure 9: Example frequency response of a conducting polymer trilayer displacement sensor (solid line). A model of the frequency response has also been fitted (broken line).

\section{CONCLUSION}

Conducting polymers are materials with a wide range of functional properties and have the potential to form all the components of a lightweight and low-cost robotic system. Before this idea can be realised, the performance of individual conducting polymer components must be improved. This paper has considered three control systems that could potentially be used to improve the performance of a bending conducting polymer actuator - feedforward gain control, feedforward inversion-based control and inversion-based proportional-integral control. It was found that an inversionbased PI control system can significantly improve the rise time, settling time, dynamic displacement and positional drift without excessive input voltages, but at the cost of requiring a large displacement feedback sensor. To overcome the need for a large external feedback sensor, a system utilising an integrated conducting polymer bending sensor was proposed.

Future research work will continue the investigation of trilayer bending actuator control [26], including the construction and characterisation of the actuator with integrated feedback. Further development of intelligent control methods will also be undertaken, including modeling of the nonlinear actuator behaviour (positional drift and hysteresis) for implementation in inversion-based control systems.

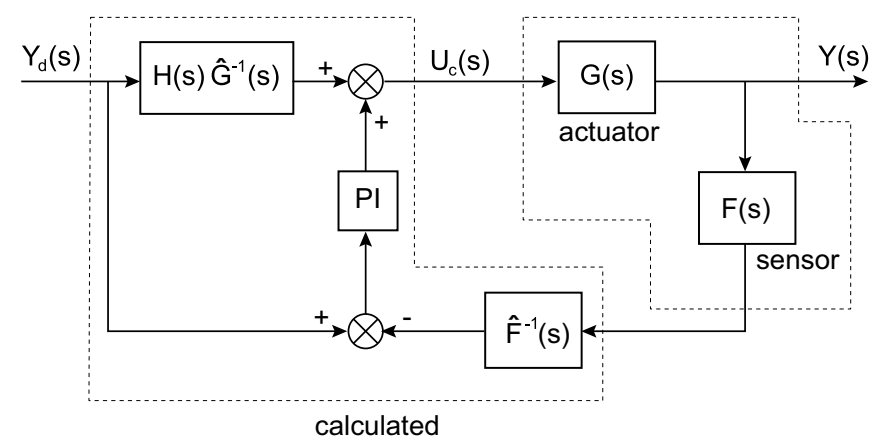

Figure 10: Schematic diagram of a conducting polymer actuator control system with integrated displacement sensor.

\section{ACKNOWLEDGMENT}

The authors would like to thank the ARC Centre of Excellence for Electromaterials Science (CE0561616) for their assistance in manufacturing the conducting polymer actuators and financial support. S.W.J. thanks N.L. for useful discussions.

\section{REFERENCES}

[1] E. Smela, "Conjugated Polymer Actuators for Biomedical Applications," Advanced Materials, vol. 15, pp. 481-494, 2003.

[2] J. D. W. Madden, B. Schmid, M. Hechinger, S. R. Lafontaine, P. G. A. Madden, F. S. Hover, R. Kimball, and I. W. Hunter, "Application of polypyrrole actuators: feasibility of variable camber foils," Oceanic Engineering, IEEE Journal of, vol. 29, pp. 738-749, 2004. 
[3] J. Janata and M. Josowicz, "Conducting polymers in electronic chemical sensors," Nat Mater, vol. 2, pp. 19-24, 2003.

[4] Y. Wu, G. Alici, J. D. W. Madden, G. Spinks, and G. G. Wallace, "Soft Mechanical Sensors Through Reverse Actuation in Polypyrrole," Advanced Functional Materials, vol. 17, pp. 3216-3222, 2007.

[5] R. H. Baughman, "Conducting polymer artificial muscles," Synthetic Metals, vol. 78, pp. 339-353, 1996.

[6] C. D. Dimitrakopoulos and D. J. Mascaro, "Organic thin-film transistors: A review of recent advances," IBM Journal of Research and Development, vol. 45, p. 11, 2001.

[7] C. Arbizzani, M. Mastragostino, and L. Meneghello, "Polymer-based redox supercapacitors: A comparative study," Electrochimica Acta, vol. 41, pp. 21-26, 1996

[8] J. G. Killian, B. M. Coffey, F. Gao, T. O. Poehler, and P. C. Searson, "Polypyrrole Composite Electrodes in an All-Polymer Battery System," Journal of The Electrochemical Society, vol. 143, pp. 936-942, 1996.

[9] S.-S. K. J. J. D.-Y. K. Seok-In Na, "Efficient and Flexible ITO-Free Organic Solar Cells Using Highly Conductive Polymer Anodes," Advanced Materials, vol. 20, pp. 4061-4067, 2008

[10] H. Sirringhaus, T. Kawase, R. H. Friend, T. Shimoda, M. Inbasekaran, W. Wu, and E. P. Woo, "High-Resolution Inkjet Printing of All-Polymer Transistor Circuits," Science, vol. 290, pp. 2123-2126, December 15, 20002000.

[11] G. Alici and N. N. Huynh, "Performance quantification of conducting polymer actuators for real applications: a microgripping system," IEEE/ASME Transactions on Mechatronics, vol. 12, pp. 73-84, 2007.

[12] G. Alici, G. Spinks, J. D. W. Madden, Y. Wu, and G. G. Wallace, "Response Characterisation of Electroactive Polymers as Mechanical Sensors," IEEE/ASME Transactions on Mechatronics, vol. 13, pp. 187196, 2008.

[13] S. John, G. Alici, and C. Cook, "Validation of a Resonant Frequency Model for Polypyrrole Trilayer Actuators," IEEE/ASME Transactions on Mechatronics, vol. 13, pp. 401-409, 2008.

[14] Q. Yao, G. Alici, and G. M. Spinks, "Feedback control of tri-layer polymer actuators to improve their positioning ability and speed of response," Sensors and Actuators A, vol. 144, pp. 176-184, 2008.

[15] S. Hara, T. Zama, W. Takashima, and K. Kaneto, "Free-standing gellike polypyrrole actuators doped with bis(perfluoroalkylsulfonyl)imide exhibiting extremely large strain," Smart Materials and Structures, vol. 14, pp. 1501-1510, 2005.
[16] T. Zama, S. Hara, W. Takashima, and K. Kaneto, "Comparison of Conducting Polymer Actuators Based on Polypyrrole Doped with BF4-, PF6-, CF3SO3- and ClO4-," Bull. Chem. Soc. Jpn., vol. 78, pp. 506$511,2005$.

[17] J. D. Madden, R. A. Cush, T. S. Kanigan, and I. W. Hunter, "Fast contracting polypyrrole actuators," Synthetic Metals, vol. 113, pp. 185$192,2000$.

[18] G. M. Spinks, B. Xi, D. Zhou, V.-T. Truong, and G. G. Wallace, "Enhanced control and stability of polypyrrole electromechanical actuators," Synthetic Metals, vol. 140, pp. 273-280, 2004

[19] Y. Fang, X. Tan, and G. Alici, "Robust Adaptive Control of Conjugated Polymer Actuators," IEEE Transactions on Control Systems Technology, vol. 16, pp. 600-612, 2008.

[20] S. W. John, "Modelling and Control of Conducting Polymer Actuators," in School of Mechanical, Materials and Mechatronic Engineering. vol. $\mathrm{Ph}$.D. Wollongong: University of Wollongong, 2008.

[21] S. John, G. Alici, and C. Cook, "Frequency response of polypyrrole trilayer actuator displacement," in Electroactive Polymer Actuators and Devices (EAPAD) 2008, San Diego, California, USA, 2008, pp. 69271T-8.

[22] J. D. W. Madden, P. G. A. Madden, and I. W. Hunter, "Polypyrrole actuators: modeling and performance," in Smart Structures and Materials 2001: Electroactive Polymer Actuators and Devices, 2001.

[23] W. Takashima, K. Hayasi, and K. Kaneto, "Force detection with Donnan equilibrium in polypyrrole film," Electrochemistry Communications, vol. 9, pp. 2056-2061, 2007.

[24] W. Takashima, T. Uesugi, M. Fukui, M. Kaneko, and K. Kaneto, "Mechanochemoelectrial Effect of Polyanaline Film," Synthetic Metals, vol. 85, pp. 1395-1396, 1997.

[25] S. W. John, G. Alici, G.M. Spinks, J. M. D. Madden, and G.G. Wallace, "Towards fully optimised conducting polymer bending sensors: Effect of geometry", Journal of Smart Materials and Structures, 2009. (In print)

[26] S. W. John, G. Alici, and C. D. Cook, " Inversion-based Feedforward Control of Polypyrrole Trilayer Bender Actuators", IEEE/ASME Transactions on Mechatronics, 2009. (In Print) 